565. Lin, S., \& Slovic, P. (2003, August). Sign Theory: A non-extensional theory of preference (Report No. 06-03). Eugene, OR: Decision Research.

\title{
SIGN THEORY: A NON-EXTENSIONAL THEORY OF PREFERENCE
}

Shuyeu Lin

Minghsin University of Science and Technology

Paul Slovic

Decision Research

and University of Oregon

Corresponding author:

Paul Slovic

Decision Research

1201 Oak Street

Eugene, OR 97401

(Voice): 541-485-2400

(FAX): 541-485-2403

(Email):pslovic@darkwing.uoregon.edu 


\begin{abstract}
A non-extensional theory of preference, called Sign Theory, is proposed and tested. Sign Theory considers preference construction as an evidence-building process, in which local valuation of evidence combines additively to form a global judgment. At the heart of this treatment is the notion that local evaluation generates positive or negative valuation outcomes (signs). Thus, signs are building blocks for preference construction. Study 1 confirmed the notion that valuation processes are based on signs derived from reference points. Studies 2 and 3 demonstrated the robustness and importance of the sign-frequency effect, which shows that the attractiveness of an option is positively related to the number of the positive signs, but negatively related to the number of negative signs. Studies 4 and 5 were designed to reduce the sign-frequency effect. Study 4 provided information about attribute weights to help participants appreciate the part-whole relationship between partitioned attributes and summarized attributes. In Study 5, decision makers were clearly informed about the two display formats of the same information. Nevertheless, in both studies, the presence of sign-frequency effects remained evident.
\end{abstract}

Key words: Sign Theory, reference point effects, sign-frequency effects, preference construction. 
What most distinguishes decision making from other thinking is that it not only requires decision makers to have an adequate model of the world but also a model of themselves. A decision process starts when one recognizes the need to change one's present state, and culminates when one is able to discern the desirability of the options with respect to oneself. Decision-making is, therefore, a value-driven process. One does not always know what one wants in life, and probably few ever know this with great certainty. Nevertheless, a primary value system typically works well to guide us through daily life. It informs us about what to look for, what is significant to us in a complex environment. Thus it provides us with decision criteria to narrow the range of information we must consider and it promotes real-time responses. The failures of such a system can have devastating consequences. An extreme example is illustrated by Dante's perplexed soul who, unable to decide between two equally attractive foods, died of starvation (see Slovic, 1975). Inaction, in this case, is not due to the complexity of the task, but to a disconnection between problem solvers and their needs.

The problem of preference has been simplified in rational models of decisionmaking. In Subjective Expected Utility Theory (SEU), for example, all uncertainty is loaded into states of the world, and the actors are assumed to have perfect self-knowledge regarding their preferences. The strongest challenge to this conception are the findings that violate the logic of extensionality (or invariance), which states that judgments and decisions about events with the same extension should not be influenced by the way those events are described. However, evidence of framing effects points to the contrary (for example, see Tversky \& Kahneman, 1986). One form of the violation of extensionality is the observation that people's evaluation of the same event differs depending on the level of detail with 
which the event is described and evaluated. For example, the splitting biases, well documented in the application of multi-attribute utility decision theory (MAUT), indicate that the sum of the sub-attribute weights is often significantly higher than the weight of the summarized attribute (for a review, see Weber, Eisenfuhr, \& von Winterfeldt, 1988). In terms of experienced utility, the judgment of an affective experience as a whole is found to be quite different from the summation of momentary affective experiences across time (Fredrickson \& Kahneman, 1993). There is also a great deal of evidence indicating violations of extensionality in probability judgments (Rottenstreich \& Tversky, 1997; Tversky \& Koehler, 1994).

We believe that the common failure of extensionality is an essential feature of human judgment. This study proposes that a main cause of such violations is the characteristic nature of a primary, affective valuation process. A theory of preference, called Sign Theory, is presented here to capture some of the important characteristics in this valuation process. In contrast to value-based choice theories, such as Expected Utility Theory, there are three key features in Sign Theory: (1) the carrier of value is the actual representation (or descriptions) of the object, not the object in abstraction. (2) Evaluation is based on classified values (signs), not unclassified values. (3) The choice rule is the maximization of signs, not the maximization of unclassified values.

\section{SIGN THEORY}

In line with the interpretation of choice as a constructive process (Slovic, 1995; Payne et al., 1999), Sign Theory considers preference construction as an evidence-building process, in which local evaluation of evidence combines additively to form a global judgment. At the heart of this treatment is the notion that local evaluation generates positive 
or negative valuation outcomes (signs). Thus, detailed descriptions of an object generate more signs, while global descriptions generate fewer signs. Local evaluation is closely related to a primary valuation process, which is often affective in its core. Yet the outcomes of primary valuation, which guide expressed preferences, are susceptible to contextual influences. For instance, Levin et al. (1988) found that people react differently to the same package of meat depending on whether it is described as containing $25 \%$ fat or as being 75\% lean. From Sign Theory's perspective, people are consistent in their primary valuations regarding the fat information in food, in that they generally react positively to fat-free designations, and negatively to descriptions of the presence of fat. Yet for that very reason, their expressed preference is influenced by how the \% fat information is presented. Thus, "preferences” do exist, but not in the sense in which they are conceptualized in normative theory (see Kahneman, Ritov, \& Schkade, 1999).

Sign Theory assumes: (1) that people classify objects of valuation into valuation units, and (2) that the valuation outcomes are positive or negative signs, derived from classifying information with respect to one’s reference point. Together, (1) and (2) represent reference point effects. (3) The attractiveness of an option is positively correlated with the number of positive signs, and negatively correlated with the number of negative signs. This is called the sign-frequency effect.

\section{Reference Point Effects}

Let $\mathrm{V}($.$) denote the valuation function of an object. A set of possible outcomes of$ $\mathrm{V}($.$) can then be represented as \{1$ (positive), 0 (neutral), -1 (negative) $\}$. Note that the "neutral” outcome may occur when, in the absence of a reference point, the stimulus is not 
classified and thus does not carry affective value. There are two implications that can be drawn from this formulation:

First, the easy-to-classify dimensions should receive more weight in a decision than the hard-to-classify dimensions. This is because classified information carries affective value (meaning), while unclassified information does not. We like (+) or dislike (-) someone who matters to us (a significant other); otherwise, we simply feel indifferent (0, unclassified information). That is, the absolute value of either 1(classified, +) or 1(classified, -) is larger than 0 (unclassified, neutral).

Second, after classification, the sign pattern (positive or negative) induced by the introduction of a reference point impacts preference. Thus, although objectively there is little difference between winning $\$ 1$ and losing $\$ 1$ in terms of one’s overall assets, psychologically a win (affective value +1 ) is better than a loss (affective value -1 ).

Reference point effects demonstrate that judgment and choice are not based on an “objective” stimulus as it is presented in a decision context (see Chiu \& Lin, 2002; Kahneman, 1992). Rather, they are often based on "classified" information, which carries an affective valuation message (e.g., gain-loss, good-bad). Some suggest that the function of the reference point is to simplify information in a complex world (Simon, 1955, 1956). Problems of complexity and meaningfulness are hard to disentangle in a decision context, and often are two sides of the same coin. But deriving affective meaning from otherwise hard-to-evaluate data does not always reduce the complexity of stimuli. Children can well appreciate \$20 in income from their lemonade stand. Adults, on the other hand, understand that earning \$20 does not indicate success until one knows the costs of doing business. In 
this case, assessing profit using a reference point (cost) is more complicated than assessing it without a reference point, but it is certainly more meaningful.

The psychological study of attitudes and emotions may provide a broader framework for understanding affective valuation processes. Using the semantic differential method, Osgood, Suci, and Tannenbaum (1957) have identified an important factor that emerges from factor analysis to determine the affective meaning of an object. This is the evaluative factor, so labeled because it includes affective dimensions such as GOOD-BAD, and BEAUTIFUL-UGLY. According to Osgood et al. (1957), judgments tend to be most strongly determined by the evaluative factor. It is pervasive in judgment and “... appears to be primary—when asked if she'd like to see the dinosaur in the museum, the young lady from Brooklyn first wanted to know, 'Is it good or bad?’” (p.72)”. Zajonc (1980) also considered affective valuation as a primary process, in the sense that it occurs before conscious awareness.

This primary valuation process may be an essential mechanism for an adaptive decision maker in the face of complex and uncertain environment (Damasio, 1994; Oatley \& Johnson-Laird, 1987; Simon, 1967). It determines, in real time, the significance of incoming stimuli with respect to one's concern (reference point). This process therefore can be characterized as a quick summary impression, and the gist of it is to disclose the affective meaning of the stimuli.

\section{The Sign-Frequency Effect}

Assuming that signs are the outcomes of the valuation units, Sign Theory predicts a “sign-frequency effect,” whereby the attractiveness of an option is positively related to the number of the positive signs, but negatively related to the number of negative signs. 
Let A represent the property to be evaluated. It can represent an object (e.g., a computer), the components of the object (e.g., the monitor), the attributes of the component (e.g., picture quality of the monitor), or the sub-attributes of the attribute (e.g., color fidelity), and so forth. In principle, the evaluation can occur at whatever level of detail is presented. Let $\{a, b, c, \ldots ., n\}$ denote a finite set of descriptions (e.g., color fidelity, picture clarity, picture contrast) that describe or define the property A at an upper level (e.g., picture quality). Let $\mathrm{V}(\mathrm{A})$ represent the valuation at the level $\mathrm{A}$, when detailed information about $\mathrm{A}$ is not given; and let $\mathrm{V}(\mathrm{A} \mid \mathrm{a}, \mathrm{b}, \mathrm{c}, \ldots . . \mathrm{n})$ denote the valuation at the level $\mathrm{A}$, given that lower level descriptions $\{a, b, c, \ldots ., n\}$ are available. For example, in the store, computers are often displayed and sold in a "package," where all the detailed information (about the monitor, printer, software, etc) is available. Let $\mathrm{V}(\mathrm{a})+\mathrm{V}(\mathrm{b})+\ldots .+\mathrm{V}$ (n) indicate that the evaluation is done at sub-attribute level of A, separately for each component, and then added up to represent the overall value of A. The sign-frequency effect predicts that, Given a set of positive descriptions $\{a, b, c, \ldots . ., n\}$, then

$$
\begin{aligned}
& \mathrm{V}(\mathrm{A})<\mathrm{V}(\mathrm{a})+\mathrm{V}(\mathrm{b})+\ldots \ldots .+\mathrm{V}(\mathrm{n}) \\
& \mathrm{V}(\mathrm{A} \mid \mathrm{a}, \mathrm{b}, \mathrm{c}, \ldots . \mathrm{n})<\mathrm{V}(\mathrm{a})+\mathrm{V}(\mathrm{b})+\ldots \ldots . . \mathrm{V}(\mathrm{n})
\end{aligned}
$$

Given a set of negative descriptions $\{\mathrm{a}, \mathrm{b}, \mathrm{c}, \ldots . ., \mathrm{n}\}$, then

$$
\begin{aligned}
& \mathrm{V}(\mathrm{A})>\mathrm{V}(\mathrm{a})+\mathrm{V}(\mathrm{b})+\ldots \ldots .+\mathrm{V}(\mathrm{n}) \\
& \mathrm{V}(\mathrm{A} \mid \mathrm{a}, \mathrm{b}, \mathrm{c}, \ldots . \mathrm{n})>\mathrm{V}(\mathrm{a})+\mathrm{V}(\mathrm{b})+\ldots \ldots .+\mathrm{V}(\mathrm{n})
\end{aligned}
$$

Note that, even when the availability of information is equivalent at both ends of the equation, there is a difference in terms of the number of valuation units involved (Equations 2 and 4). On the left side of these two equations, there is only one valuation unit (e.g., 
evaluate the computer package as a whole, given all the component information that is available). Therefore this only creates one Good/Bad valuation outcome. On the other hand, there are more valuation units at the right side of equations 2 and 4 and this creates more Good/Bad valuations. A notable feature of Sign Theory is that it considers the frequency of valuation units, not simply the availability of the details, to be the major determiner of judgments and decisions. Therefore, Sign Theory does not predict any specific relationship between $\mathrm{V}(\mathrm{A})$ and $\mathrm{V}(\mathrm{A} \mid \mathrm{a}, \mathrm{b}, \mathrm{c}, \ldots . . \mathrm{n})$. Giving a detailed description of an attraction may help in some cases, but not always. Having a romantic idea about a vacation in Paris without knowing anything about Paris may or may not be more appealing than knowing all the specifics.

It is important to note that Sign Theory does not suggest that an attribute's weight and its quantity do not play a role in a decision. They may have impact, to some extent, at the later stage of a decision process. It is not a contradiction to Sign Theory to consider that different attributes, or their signs, carry different weights in a decision. Indeed, given a set of attributes, the more important attribute is known to be an important determinant of choice (Slovic, 1975; Tversky, Sattath, \& Slovic, 1988). However, Sign Theory predicts a diminished role for the hard-to-classify quantitative information in a decision, mainly because of the difficulty of deriving its affective meaning. A similar concept was expressed by Hsee (1996) in his “evaluability hypothesis,” in which he suggested that hard-toevaluate attributes tend to receive less weight in judgment.

The primary valuation is more sensitive to the affective direction of the stimulus (sign, + or -) than to its intensity. This is especially evident in the applications of contingent valuation, where the market values of the goods of interest are unknown. 
Kahneman and Knetsch (1992) found that Toronto residents were willing to pay only a little more to clean up all the polluted lakes in Ontario than to clean up polluted lakes in a small region of Ontario. When Desvousges et al. (1992) asked people how much they were willing to pay to save birds, mean WTP was $\$ 80$, $\$ 78$ and $\$ 88$, respectively, for saving 2,000, 20,000 or 200,000 birds annually. A case can be made from these findings that, without the benefit of the familiar market price structure, people can only meaningfully express their primary affective valuation or moral judgment in sign (positive in these cases), and not in intensity. In the language of affect, the loss of ten human lives is a tragic event; so is the loss of one human life. It is doubtful if one can meaningfully conclude that the former event is 10 times more tragic than the latter. However, from the perspective of Sign Theory, the loss of ten human lives in total in ten unrelated events will be considered as ten tragedies, and consequently carry more affective value than that of one tragedy that takes 10 lives. An emotional event, big or small, constitutes one valuation unit. What is important is the number of valuation units involved, not their intensity. The prosecutor in Timothy McVeigh’s trial apparently followed the same "affective algebra," when he reminded the jurors not to see the Oklahoma City bombing as one tragedy, but 168 separate, individual tragedies.

The effect of splitting valuation units is well documented in the application of multi-attribute utility decision theory (MAUT) where the assessment of attribute weights in a value tree is an important input for the model. From a prescriptive viewpoint, the description of the attribute should not have an influence on its weight (description invariance). For example, following MAUT, a larger range of the attribute should result in a larger weight of the attribute. When considering job offers, a range of earnings from 
$\$ 40,000$ to $\$ 50,000$ has to be given less weight than a range from $\$ 40,000$ to $\$ 80,000$. Von Nitzsch and Weber (1993) asked participants what range came to their mind when they thought about the attribute "earnings per year". The results clearly indicated that participants do not adjust weights accordingly (range effect). A similar bias has been discussed under the label of splitting bias. For an additive model, the weight for any attribute should be equal to the sum of the weights of the sub-attributes. Weber, Eisenfuhr, and von Winterfeldt (1988) asked participants to assign weights to a value tree that included the target attribute. Another version of the value tree was generated by splitting the target attribute into two sub-attributes, and asking participants to assign weights at the level of the sub-attributes. The results indicated that the sum of the sub-attributes weights was significantly higher than the weight of the single target attribute.

\section{RESEARCH DESIGN}

Key assumptions in Sign Theory regarding (1) valuation units, and (2) the signfrequency effect were discussed in previous sections. There were several testable hypotheses derived from those two assumptions, and five studies were designed to test these hypotheses. They are organized as shown below:

1. Valuation Units. One of the testable hypotheses derived from the notion of reference point effects is that, after classification, the sign pattern (positive or negative) induced by the introduction of the reference point predicts an abrupt change of preference or judgment (Kahneman, 1992). Study 1 was designed to test this hypothesis.

2. Studies 2 and 3 were designed to test the prediction of sign-frequency effects and their relative importance in a decision. Study 2 employed choice tasks to examine the sign- 
frequency effect and the effect of enhanced availability. Study 3 investigated signfrequency effects using willingness-to-pay as the response, and contrasted the signfrequency effect with the effect of the more important dimension.

3. Studies 4 and 5 were designed to reduce the sign-frequency effects. In study 4 , participants were informed of the attribute weights and the weights of sub-attributes. In study 5, participants were informed of two possible display formats before they made a decision.

\section{STUDY 1}

Study 1 was designed to make both dimensions in the task equally easy to classify, thus the overall sign pattern should determine the decision outcomes. Participants were asked to choose a secretary based on two pieces of information: the quality and the speed of typing, where typing quality was assumed to be a more important dimension as shown by Slovic (1975).

\section{Method}

$\underline{\text { Participants }}$

Participants in this study were 79 students from the University of Oregon who participated to fulfill the requirements for a psychology class.

\section{Design and Procedures}

Participants were instructed to consider four choice tasks (see column 2 in Table 1) in a hypothetical hiring decision situation. The instruction was as follows:

"Imagine the following: You are the owner of a small business firm. You plan to hire a secretary. So far there are two candidates that interest you. They are equally qualified 
in all aspects except for typing ability and speed. You rated each candidate’s typing QUALITY and SPEED on an $11(0-10)$ point scale, where 0 represents a VERY BAD rating, 5 represents AVERAGE, and 10 represents a VERY GOOD rating. In the following, you will see the two candidates' ratings on typing QUALITY and SPEED. Choose one candidate based on this information. Please treat each question independently.”

An example of the task (pair 1 ) is as follows:

$$
\text { Quality } \quad \underline{\text { Speed }}
$$

Candidate A: $\quad 8 \quad 6$

Candidate B: $\quad 6 \quad 9$

\section{$\underline{\text { Predictions }}$}

In this study, the average rating " 5 ” is assumed to be the reference point participants use to classify the rating scores. Therefore, rating scores above 5 will be coded as “+,” and rating scores below 5 will be coded as “-” (see column 3 in Table 1).

Insert Table 1 about here

Note that, in this study, both dimensions have equally clear reference points (rating scale 5). Therefore, signs of both dimensions are important in determining choices. More specifically, when the sign patterns are unequal between the two candidates, as in pairs 2 and 3, the candidate with more positive signs (or fewer negative signs) is predicted to be chosen. Second, when the sign patterns are identical for both candidates, as in pairs 1 and 4, participants are predicted to choose the candidate who has a better rating on the more important dimension (typing quality), consistent with the prominence effect (Tversky, Sattath, \& Slovic, 1988). 


\section{Results and Discussion}

The choice percentages are presented in the last column in Table 1.

As predicted by the important dimension effect, in choice pairs 1 and 4, most participants (86\% in pair 1 , and $84 \%$ in pair 4 ) chose candidate $\mathrm{A}$, who had the better rating on typing quality. In pairs 2 and 3, however, most participants chose the candidate who had more positive signs (67\% chose candidate B in pair 2, and $90 \%$ chose candidate A in pair 3).

It is instructive to compare the results of pair 1 and pair 2 . The only difference between these two pairs was in the rating of typing speed. Both candidates’ typing speed ratings in pair 2 were two points lower than in pair 1. From a normative viewpoint, the preference should be the same in both pairs (based on the independence principle). However, the results show a strong reversal of preference (86\% chose A in pair 1, and 33\% chose $\mathrm{A}$ in pair 2). Similarly, comparing pairs 2 and 3, the typing quality attribute in pair 3 was two points lower than in pair 2, and the typing speed attribute was two points higher than in pair 2. Again, the preference was reversed (33\% chose A in pair 2, and $90 \%$ chose A in pair 3). This abrupt change of preference reflects the change in sign pattern induced by the reference point effect. Although typing quality is a more important dimension in this decision context, the sign pattern, not the more important dimension, appeared to dominate the choice.

\section{STUDY 2}

The main purpose of Study 2 was to further examine the influence of the signfrequency effect on choice. More specifically, this study sought to test the predicted effects of partitioning a positive attribute and a negative attribute. The enhanced availability 
hypothesis was also tested, for it predicts $V(A)<V(A \mid a, b, c, . . . n)$ if target attribute $A$ is a positive attribute, and predicts $V(A)>V(A \mid a, b, c, . . . n)$ if $A$ is a negative attribute. Sign Theory does not predict such effects.

\section{Method}

\section{$\underline{\text { Participants }}$}

Participants in this study were 164 students from the University of Oregon who participated to fulfill a requirement for a psychology class.

\section{$\underline{\text { Design and Materials }}$}

The questionnaire had three between-subject versions: Fifty-five participants participated in a Summarized version, fifty-six participants participated in a Detailed version, and fifty-three participants participated in a Control version. Each version contained eight choice tasks in four different decision contexts (two choice tasks for each context): TV, Health Maintenance Organization (HMO), Budget Committee, and Used Car. In the choice task, the participant was asked to indicate their preference between two options. The information about each option was sometimes presented in summarized format without the description of sub-attributes (Control version), sometimes presented in summarized format with the description of sub-attributes (Summarized version), and sometimes presented in detailed format where attributes were partitioned into individual sub-attributes (Detailed version).

This study manipulated two types of partition, positive (partitioning good attribute) and negative (partitioning bad attribute). Table 2 demonstrates the positive partition condition (Symbol code: $\bigcirc$ represents a good rating, $\bigcirc$ represents a bad rating, and 
represents an average rating). In the control version, there are no sub-attributes to describe the attribute of picture quality. In the summarized version, picture quality, which is described by four sub-attributes (picture clarity, color fidelity, picture brightness, picture contrast), is summarized into an overall rating of good for TV A and a rating of average for TV B. In the detailed version, picture quality is partitioned into its four sub-attributes, and they are now symbolized as four good attributes for TV A, and four average attributes for TV B.

The negative partition condition simply reflects the positive partition. As shown in Table 3, the control version has no sub-attributes to describe the bad attribute (picture quality) for TV A, and average attribute for TV B. In the summarized version, picture quality is described by overall ratings on four sub-attributes. In the detailed version, the sub-attributes are now split into four bad attributes for TV A, and four average attributes for TV B.

Insert Tables 2 and 3 about here

Likewise, in the HMO choice question, the attribute Treatment Quality in the summarized version was split into three attributes (thoroughness of treatment patients receive, how difficult it was to receive care patients believed was necessary, how difficult it was to get approval to see a specialist) in the detailed version. In the Budget Committee choice, the attribute Social Services was split into four attributes (community center, recreation facilities, public library, helping homeless people) in the detailed version. In the Used Car choice, the attribute Reliability Record was split into four attributes (engine 
reliability, electrical system reliability, steering/suspension reliability, exhaust system reliability) in the detailed version.

In the choice task, participants were asked to indicate their preference on a ninepoint preference scale, where preference ratings 1-4 indicated a choice for option A, 5 indicated no preference, and 6-9 indicated a choice for option B. After performing the two choice tasks (positive and negative partition) in each decision context, participants were asked to indicate how familiar they were with that decision context, using a familiarity scale ranging from 0 (not at all familiar) to 10 (extremely familiar). The mid-point on the scale, 5, was labeled as moderately familiar.

Overall, each participant answered 8 choice tasks ( 2 choices X 4 decision contexts) and 4 familiarity ratings ( 1 rating $X 4$ decision contexts).

\section{Predictions}

1. (1) From a normative viewpoint, the detailed and summarized versions describe the same options. According to Sign Theory, however, the frequency of good or bad attributes matters. Therefore, comparing detailed and the summarized versions, the positive partition should increase the attractiveness of the detailed version, while the negative partition should decrease it. (2) For the detailed and control versions, the sign-frequency effect also predicts that, compared to the control version, the positive partition should increase the attractiveness of the detailed version, while the negative partition should decrease it. (3) Comparing summarized and control versions, the availability hypothesis predicts that, because summarized versions have more detailed information (sub-attributes) about the target attribute, the summarized version should be more attractive than the control version in the positive partition condition, and should be less attractive than the control 
version in the negative partition condition. Sign Theory, however, does not predict such an effect. Since the number of signs is the same for both summarized and control versions, simply making detailed information available should not have an effect on choice.

2. This study also examined the possible role of familiarity in relation to signfrequency effects. It is reasonable to assume that if one is more familiar with the decision context, one is more likely to judge an option by what it "really is," not how it is presented. For example, in the detailed version of the TV task, familiarity may enable one to see that picture clarity, color fidelity, picture brightness, and picture contrast are all features of picture quality, and therefore one may "re-pack" those features into one attribute and evaluate it as one valuation unit. In other words, we may see a reduced sign-frequency effect in a more familiar decision context. To determine this at a group level, the results from the more familiar decision contexts (TV, Used Car) will be compared with the results from less familiar contexts (HMO, Budget Committee).

\section{Results and Discussion}

\section{Measures of Preference}

The results of the preference data are shown in Table 4, where the preference ratings were also translated into choice percentages.

Insert Table 4 about here

First, we conducted a two-way ANOVA (Version (detailed, summarized, control) X Direction (positive/negative partition)) for each of the four decision contexts. The results indicate significant interaction effects between Version and Direction factors at $\mathrm{p}<.01$ level for each decision context. We then conducted eight simple main effect tests for the Version 
factor, separately, at the positive and at the negative partition conditions for four decision contexts. The results again show significant interaction effects at $p<.01$ level across all but one condition ( Budget Committee decision at positive partition condition: $\mathrm{F}(2,160)=1.96$, $\mathrm{p}=.14)$. These results confirmed the general preference pattern shown in Table 4: As compared to Control and Summarized versions, the preference for option A increased in the Detailed version of the Positive Partition condition, and the preference for option A decreased in the Detailed version of the Negative Partition condition.

The main predictions in this study were summarized under Predicted Effects in Table 4, and the Least Significant Difference (LSD) procedure was used to assess these effects. The results will be discussed below.

\section{Sign-Frequency Effects (D-S), (D-C)}

As predicted, comparing detailed and summarized conditions (D-S), the positive partition (partitioning the good attribute) increased the attractiveness of option A in each of the four contexts, as indicated by the lower ratings and the higher percentage of choices for option A. For example, in the left-hand side of Table 4, the mean preference rating for TV was 5.0 in the detailed version and 6.8 for the summarized version; the choice percentage for TVA was 39\% in the detailed version and 22\% in the summarized version. Also as predicted, the negative partition (partitioning the bad attribute) decreased the attractiveness of option A, as indicated by the higher ratings and the lower percentage of choices for option A. The LSD tests indicate that the predicted sign-frequency effects were significant across all but one condition (Budget Committee task in the Positive Partition condition). 
Likewise, comparing detailed and control conditions (D-C), the sign-frequency effects were significant across all but two conditions (HMO task in Positive Partition condition, Budget Committee task in Positive Partition condition).

\section{$\underline{\text { Availability Effects (S-C) }}$}

The results in Table 4 do not support the enhanced availability hypothesis. Comparing summarized and control versions (S-C), in general the differences were small (differences were significant in only two out of eight conditions). What is more important is that the results were in the direction predicted by enhanced availability in only three out of eight conditions.

\section{Familiarity}

The manipulation check for the familiarity effect was provided by the familiarity scale: The mean familiarity score was 6.7 for the TV context (6.7 for detailed, 6.9 for summarized, 6.6 for control version), 6.3 for the Used Car context (6.7 for detailed, 5.9 for summarized, 6.4 for control version), 4.2 for the HMO context (4.5 for detailed, 3.9 for summarized, 4.2 for control version), and 3.9 for the Budget Committee contexts (4.3 for detailed, 3.2 for summarized, 3.3 for control version). There was no evidence to suggest the influence of familiarity on the sign-frequency effect. As noted earlier, in both the detailed versus summarized comparison (D-S) and the detailed versus control comparison (D-C), the sign-frequency effect was found for both more familiar and less familiar decision contexts. Further, as shown in Table 4, there were no consistent differences in the sizes of the effect between the more familiar and less familiar contexts. 


\section{STUDY 3}

Study 3 differed from Study 2 in three major respects. First, it used a judgment task, willingness-to-pay (WTP), instead of choice task. Second, it used a within-subject design, therefore allowing a closer examination of the sign-frequency effects at the individual participant level. Third, Study 3 contrasted the sign-frequency effect with the "important dimension effect”. This effect is well documented in the literature (Slovic, 1975; Tversky, Sattath, \& Slovic, 1988), and is known to be strong. In a sense, this study pits the impact of the important dimension effect versus the sign-frequency effect to gauge the relative importance of the latter in decision processes.

\section{Method}

\section{$\underline{\text { Participants }}$}

Participants in this study were 82 students from the University of Oregon who participated to fulfill the requirements for a psychology class.

\section{$\underline{\text { Design and Materials }}$}

The decision contexts in this study were the TV and HMO questions from Study 2. The questionnaire had three within-subject versions: summarized, detailed, and the partitioning of the less important dimension (PLI). The order of the three versions was randomized in the booklet.

In each version, participants were asked to consider each option and then answer “What is the most you are willing to pay for X?” After four WTP tasks in each decision 
context, participants were then asked to indicate the relative importance of each attribute in determining their judgments by dividing 100 points among all attributes.

Overall, each booklet contained 24 WTP tasks (4 tasks per decision context (options $\mathrm{A}$ and $\mathrm{B}$ in a positive partition, options $\mathrm{A}$ and $\mathrm{B}$ in a negative partition) $\mathrm{X} 2$ decision contexts (TV, HMO) X 3 versions (summarized, detailed, PLI )) and 6 relative importance rating tasks (2 decision contexts (TV, HMO) X 3 versions (summarized, detailed, PLI)).

\section{$\underline{\text { Predictions }}$}

As shown in Table 5 (positive partition condition), the sign-frequency effects were assessed by comparing summarized and detailed versions (Examples 5.1 and 5.3). The important dimension effects were assessed by comparing detailed and PLI versions, as demonstrated by Examples 5.1 and 5.2. Notice that both options have the same number of good and bad attributes (same sign pattern). The only difference is that in the detailed version, the attributes with a good rating (defining features of picture quality) are associated with the more important dimension compared to the PLI version, where the good features belong to the less important dimension of sound quality. Conversely, in the detailed version, the attribute with the bad rating is associated with the less important dimension (sound quality) compared to the PLI version's more important dimension (picture quality). The attribute, "ease of operation" is held constant across two versions. Therefore, to the extent that there is an effect of the important dimension, WTP responses should be higher for Example 5.1 than for Example 5.2.

Further, by comparing summarized and PLI versions one can also assess the relative importance of the frequency effect versus the effect of the important dimension. As 
Examples 5.3 and 5.4 below illustrate, the summarized version has the advantage of the important dimension (good rating in the important dimension, bad rating in the less important dimension), while the PLI version has the advantage of sign-frequency (it appears to have more positive signs).

Likewise, for the negative partition condition, various effects are expected to be the reflection of those in the positive partition condition.

Insert Table 5 about here

In this study, half of the tasks involved the partitioning of the "average" attribute in option B (see Tables 6 and 7). They require further clarification: We expect participants to perceive the "average" attribute in Table 6 as a "good" attribute by contrasting it to the two bad attributes in the background. In other word, these examples represent a case of the positive partition condition. Therefore, TV B is expected to be more attractive in Example 6.1 than in Example 6.3 (sign-frequency effects). On the other hand, participants should view the "average" attribute in Table 7 as a "bad" attribute relative to the two good attributes in the background. Therefore, this represents a case of negative partition, where option B is expected to be less attractive in Example 7.1 than in Example 7.3. The various predicted effects were expected to be weaker in option B (Table 7) than in option A (Table 6), this is because the good-bad classification in option B is induced by a contrast between an average rating and the good-bad ratings in the background, rather than being given directly by a good or bad rating.

Insert Tables 6 and 7 about here 
To summarize the predictions: (1) The sign-frequency effects predict that, in the positive partition condition, detailed version should have a higher WTP as compared to the summarized version. In the negative partition condition, detailed version should have a lower WTP as compared to the summarized version. The same, but weaker effects were expected for option B.

(2) The important dimension effects predict that, comparing detailed and PLI versions, WTP should be higher for options that feature good attributes in the more important dimension (detailed version). And again, the effects should be weaker for option B than for option A.

(3) There is no specific prediction regarding the relative importance of the sign frequency versus the important dimension effect. The purpose of this comparison is to use the latter as a measuring stick to gauge the magnitude of the sign-frequency effects in this type of judgment task.

\section{Results and Discussion}

Willingness-to-Pay

The results of the WTP responses are summarized in Table 8. The same data set was also analyzed at the individual level. The main predictions in this study were summarized under Predicted Effects in Table 8, and the LSD procedure was used to assess these effects. 


\section{Sign-Frequency Effects (D-S)}

First, the sign-frequency effects were significant in all conditions. For example, in the positive partition condition (partitioning good attributes), the mean WTP for TV A was \$216 in the detailed version, but only $\$ 151$ for the same TV in the summarized version. This result is also confirmed by the data analysis at the individual level (not shown in Table 8), where $74 \%$ of participants were willing to pay more in the detailed than in the summarized version. The results obtained in the negative partition condition were simply the reflection of the positive partition condition. Also as expected, the above effects were stronger for option A than Option B. For example, in the positive partition condition (see D-S in Table 8), the size of the effect in option A was \$65 for TV and \$66 for HMO, while in option B it was $\$ 41$ for TV and $\$ 20$ for HMO.

Important Dimension Effect (D-PLI)

Second, the results summarized in Tables 8 confirmed the important dimension effect for both option A and option B. For example, in the positive partition condition, the mean WTP for TV A was \$216 in the detailed version, but only \$170 for the same TV in the PLI version. And at the individual level, 58\% of participants were willing to pay more in the detailed than in the PLI version. With the exception of one data point (TV A vs. TV B in negative partition condition), the effects were stronger for option A than for option B. For example, in the positive partition condition, the size of the important dimension effect in option A was \$46 for TV and \$53 for HMO, while in option B it was \$10 for TV and \$14 for HMO. 


\section{$\underline{\text { Sign-Frequency Effects vs. Important Dimension Effects (PLI-S) }}$}

Third, the results indicated that sign-frequency effects, overall, were at least as strong as, if not stronger than the effects of the more important dimension. As shown in Table 8, all but one data point suggest that sign-frequency effects were stronger than that of the more important dimension, and in two data points the differences were statistically significant.

$\underline{\text { Ratings of Relative Importance }}$

The average relative importance ratings are summarized in Table 9. The number given in parentheses represents the sum of the partitioned attributes in the detailed version.

Insert Tables 9 about here

There were two sources of partition biases shown in Table 9: (1) detailed versus summarized versions, where picture quality was split into four components in the TV context and treatment quality was split into three components in the HMO context. In the detailed version, the sums of the partitioned attributes (as shown in the parentheses, TV picture quality: mean=64; HMO treatment quality: mean=65) were consistently higher than their respective attribute weight in the summarized version (TV picture quality: mean=45; HMO treatment quality: mean=48). (2) PLI versus summarized version, where sound quality was split into four components in the TV context and customer service was split into three components in the HMO context. Again, the sums of the split attributes in PLI version were higher than their respective attribute weight in the summarized version. These 
results are consistent with the splitting bias reported in the literature (see Weber, Eisenfuhr \& von Winterfeldt, 1988).

It is instructive to compare the weights in the summarized version to those in the PLI condition. The summarized condition can be seen as the control group to determine the "true" weight of the target attribute, that is, before they have been split into sub-attributes. Assuming the summarized version does capture what participants "really” believe is important, it is quite obvious that simply splitting a less important attribute can alter that belief. For example, most people consider picture quality as the most important attribute for a TV. In the summarized version, the average weight for picture quality was .45 in this study. Yet Table 9 shows that when a less important attribute, sound quality, was split in the PLI version, it became the most important attribute (.52). And in the HMO context, the most important attribute was treatment quality in the summarized version (.48), yet in the PLI version, customer service became the most important attribute (.45). This shift of the important dimension provides insight as to why sign-frequency effects are sometimes stronger than the effect of the more important dimension.

\section{STUDY 4}

Study 4 attempted to reduce the sign-frequency effects by providing attribute weight information for both the summarized and detailed task formats. One way to interpret signfrequency effects is that participants fail to appreciate the whole-parts relationship between the summarized attribute and partitioned attribute. In this study, we provided participants with the information regarding the weights of each attribute and its sub-attributes. The attribute weights provided in this study were collected from Study 3. 


\section{Method}

\section{Participants}

Participants in this study were 290 students from Minghsin University of Science and Technology in Taiwan who participated to fulfill the requirements for a psychology class.

\section{$\underline{\text { Design and Materials }}$}

The questionnaires have four between-subject versions: Two between-subject variables are Display Format (Detailed/Summarized) and Attribute Weight Information (With/Without). Two hundred and ninety participants were randomly assigned to one of the four versions. Two TV choice tasks (positive/negative partition) from the previous studies were used in this study.

In the instruction, all the participants were told that they were to choose between two identically priced TVs, and that Consumer Reports Magazine had provided product information based on consumer survey: the quality (good-bad) rating of the various attributes, which is represented by circle symbols. In the two conditions with attribute weight information, participants were further informed about the attribute weights of the TVs. They were told that the attribute weights information were collected from a Consumer Survey, and that attribute weights represents consumers' rating of relative importance in their purchasing decisions. But actually, the attribute weights in this study were determined by the results from previous studies. In Summarized-With Attribute Weight version, the given attribute weights were as follows: Picture Quality (45\%), Sound Quality (35\%), Ease of Operation (20\%). In Detailed-With Attribute Weight version, the given attribute weights were: picture clarity (15\%), color fidelity (10\%), picture 
brightness (10\%), picture contrast (10\%), Sound Quality (35\%), Ease of Operation $(20 \%))$.

In each version, participants were first asked to indicate their preference on a sevenpoints preference scale, where 1-3 represented preference for TV A, 4 represented indifference, and 5-7 represented the preference for TV B. After performing the two choice tasks (positive and negative partitions), participants were then asked to indicate the relative importance of each attribute in determining their choices by dividing 100 points among all attributes.

\section{RESULTS AND DISCUSSION}

\section{Measures of Preference}

The results of the preference data are summarized in Table 10, where the preference scores were also translated into binary choice data.

Insert Table 10 about here

A two-way ANOVA was conducted separately for positive and negative partition conditions. The results indicated the presence of the sign-frequency effect $(F(1,285)=5.7, p$ $<.05$ for the positive partition; $\mathrm{F}(1,285)=72.3$, $\mathrm{p}<.01$ for the negative partition). However, there were no significant effects for the attribute weight manipulation $(F(1,285)=2.8$, $\mathrm{p}=.093$ for positive partition; $\mathrm{F}(1,285)=.678, \mathrm{p}=.411$ for negative partition).

For example, in the positive partition condition, TV A is relatively more preferred in detailed format than in the summarized format, with or without attribute weight information. This is indicated by the lower preference score for detailed format and higher 
choice percentage of TV A for detailed format. The observed preference pattern reversed in the negative partition condition.

\section{$\underline{\text { Ratings of Relative Importance }}$}

There was no effect of Attribute Weight manipulation as indicated by the similar ratings between With and Without Attribute Weight information conditions. On the other hand, the effects of the partition biases were evident: while the relative importance ratings in all summarized conditions were almost identical to the weights provided in this study (picture quality $=.45$, sound quality $=.35$, ease of operation $=.20$ ), the sum of the partitioned attributes in all detailed conditions deviate from what were provided in this study in the predicted direction (With Attribute Weight condition: sum of the sub-attributes of picture quality was .65 in positive partition condition and .66 in negative partition condition; Without Attribute Weight condition: sum of the sub-attributes of picture quality was .68 in positive partition condition and .70 in negative partition condition ).

The purpose of this study was to inform participants the attribute weights in order to help them appreciate the relationship between part-whole representations. The results suggest that this manipulation was not effective in reducing the sign-frequency effects.

\section{STUDY 5}

In Study 5 participants were informed (warned) that the display format of the target attribute could be in either "summarized format," or "detailed format” and later were asked to fill out a choice questionnaire that included both formats in the context of the HMO decision. 


\section{Method}

One hundred-thirteen students at the University of Oregon participated in this study. Participants were paid to complete a one-hour questionnaire, in which the present study was embedded.

\section{Design and Materials}

Participants were asked to imagine that “At some universities students must enroll in a health plan when they enroll in school. In this task we would like you to choose between two HMOs available to students, picking the plan you think will take the best care of members like yourself.” The following instructions were designed to inform participants about two display formats in the tasks:

"Some advice: Sometimes an attribute of an HMO is composed of several aspects. For example, the attribute Preventive Medical Care is made up of three specific aspects:

Preventive Medical Care

Ease of getting immunizations (e.g. flu shots, hepatitis shots)

Ease of getting screening tests (e.g., cholesterol tests, pap smears) Ease of getting physical exams
HMO A HMO B

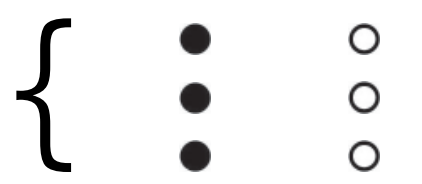

Note that HMO A is better than HMO B on all three aspects of preventive care.

Sometimes the information may be summarized as follows:

\section{Preventive Medical Care}

Ease of getting immunizations (e.g. flu shots, hepatitis shots)

Ease of getting screening tests (e.g., cholesterol tests, pap smears)

Ease of getting physical exams
HMO A HMO B

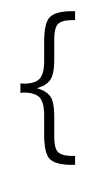

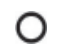


Again this means that HMO A is above average on all three aspects of preventive care and HMO B is below average on all three of these aspects.

Sometimes people give more weight to an attribute when it is not summarized, as in the top example. Try not to do this. Because the information is really the same in the summarized and non-summarized displays, you should weight summarized and nonsummarized attributes the same way when making your choice. If the attribute is important, then you should give it the same high weight, regardless of whether it is summarized or not. If it is not important, give it little weight regardless of whether it is summarized or not.”

After reading these instructions, participants were given either Choice 1, with HMO plans A and B, or Choice 2, again with HMO plans labeled A and B. The plans are shown in Tables 11 and 12. Note that each plan is described on three attributes -- customer service, preventive medical care, and treatment quality -- and each attribute has three measures. In Choice 1 the measures for customer service and preventive medical care are summarized into one overall assessment (summarized format). However, treatment quality is left partitioned into its three component measures. For Choice 2 (Table 12), the plans are essentially the same as the plans in Choice 1, except that customer service is partitioned and treatment quality is summarized (detailed format).

Insert Tables 11 and 12 about here

Participants indicated their preferred plan using the 7-point preference scale, where 1-3 represented preference for HMO A, 4 represented no preference, and 5-7 represented preference for HMO B. After expressing their preference, participants were asked to divide 100 points over the three attributes (customer service, preventive care, and treatment 
quality) to indicate the relative importance of each attribute in determining the choice they had just made.

Half of the participants did Choice 1 first. Then after completing a few unrelated tasks they were given Choice 2. The remaining 45 participants did Choice 2 first and later were given Choice 1.

\section{$\underline{\text { Predictions }}$}

If the “warning” manipulation worked, people’s preferences in Choice 1 and in Choice 2 should be the same. However, if it did not work, the sign-frequency effect observed in previous studies predicts that HMO A should be more attractive to people in Choice 2 than in Choice 1, because there are more positive signs and less negative signs in Choice 2. The opposite is predicted for HMO B. In other word, HMO A should be relatively more preferred in Choice 2 and HMO B should be relatively more preferred in Choice 1.

\section{Results and Discussion}

The results, shown in Table 13, exhibit strong preference shifts in the direction predicted by sign-frequency effects. Eighteen of the 57 participants in Group 1 expressed greater preference for HMO A under Choice 2 and 7 actually reversed their preference, going from B to A. Few shifted or reversed preferences in the opposite direction. Similarly, in Group 2, twenty participants shifted their preference in the direction of Plan B, going from Choice 2 to Choice 1, and 12 actually reversed their preference going from A to B. Two participants shifted in the opposite direction but none reversed their preference.

Insert Table 13 about here 
Thus, despite the instruction about two display formats, across both groups (a total of 113 participants), 34\% shifted their second preference in the direction predicted by signfrequency effect, and 17\% actually reversed their preference, going from A to B or viceversa upon seeing the same pair of plans a few minutes after making their first choice.

The implications of the choice data indicate that our participants were not weighting the measures or attributes consistently from the first choice to the second but, rather, were influenced by the number of circles used to describe them. In this light, it is surprising to examine the mean subjective weighting factors in Table 14, representing the way that participants thought they had used the attributes in the decision they had just made. The results in Table 14 show very little variation of subjective weights between Choice 1 and Choice 2.

Insert Table 14 about here

Recall that in Study 3 and 4, participants were asked to evaluate the weights on the partitioned components of the target attribute. Those weights were then added up to represent the weight of the target attribute. Thus sign-frequency effects predict the consistent preference pattern between participants' subjective weighting and their choice, that is, both reflect the number of positive and negative signs represented in the task. However, in Study 5 participants were asked to rate the relative importance at the level of three main attributes (treatment quality, preventive medical care, and treatment quality) regardless if those attributes were presented in summarized or detailed formats. Thus, the sign-frequency effect predicted an inconsistent preference pattern between subjective weighting and choices. The results in Table 14 support this prediction. 
If Table 14 represents the way that participants thought they had used the attributes in the decision they had just made, the results show that participants were not aware of the strong influence the display format (summarized vs. detailed) was having upon their choices.

\section{GENERAL CONCLUSIONS}

Sign Theory assumes: (1) that people classify objects of valuation into valuation units, and (2) the outcomes of these valuation units are positive and negative signs, derived by classifying information with respect to one's reference point. (1) and (2) represent reference point effects. (3) The attractiveness of an option is positively correlated with the number of positive signs, but negatively correlated with the number of negative signs. This is called the sign-frequency effect.

An implication of the reference point effects is that different sign patterns (+ or -) of classified information should produce an abrupt change of preference or judgment. This implication was investigated and confirmed in Study 1.

Studies 2 and 3 (as well as a similar study by Lin (1999), in which the attractiveness rating was used as measuring scale) examined sign-frequency effects on preferences. Altogether, there were four measuring scales used: a preference rating, WTP, attractiveness rating, and a rating of relative importance of attributes. The decision context ranged from very familiar (e.g., choosing TV) to very unfamiliar (e.g., choosing a health maintenance organization, HMO). Also, both between- and within-subject data were collected. Across all four measurements and conditions, the results all confirmed the sign-frequency effect, demonstrating the stability and robustness of sign-frequency effects. 
Study 3 also found that the sign-frequency effects at least matched and, at times, even outweighed, the effect of the more important dimension. The results are consistent with findings in Study 1: although typing quality is a more important dimension in choosing a secretary, the overall sign pattern, not the more important dimension, appeared to dominate the choice. These findings testify to the importance of sign-frequency considerations in decision-making processes. In many cases, this tendency can easily lead to undesirable decision outcomes. In our TV task, for example, most participants agreed that picture quality was the more important dimension, but they were willing to pay more for a TV with poorer picture quality than a matched priced TV with better picture quality, simply because the former had more detailed descriptions of good sound quality.

Studies 4 and 5 were designed as attempts to reduce the sign-frequency effect. Study 4 provided information of the attribute weights to help participants appreciate the whole-part relationship between a summarized and a partitioned attribute. Study 5 provided the strongest test of the sign-frequency effect thus far. Participants were clearly informed about the two possible display formats (summarized and detailed) of the same information, and then evaluated both formats within a few minutes time. Yet in both studies 4 and 5, the presence of sign-frequency effects remained evident.

The effect of stimulus frequency has been a subject of considerable interest outside of mainstream decision research. Such studies may shed light on the issues regarding what psychological processes may lead to the frequency effect, and why people are often unaware of the influence of frequency information. Hasher and Zacks (1984) reviewed a body of research on memory. They suggested that frequency information is "fundamental information” and may be acquired with very little effort and perhaps unconsciously 
(automatic encoding). Such findings have led many researchers to propose that frequency information has a special representational status. Hintzman (1976), for example, suggested a multiple trace theory of memory to represent a memory system that establishes a separate trace for each attended occurrence. Multiple trace theory proposes a sort of "frequency counter” in memory, with which one encodes each encounter separately. Estes (1976a, 1976b) considered frequency information to be the "basic knowledge" from which one derives probability judgments. Gigerenzer and Hoffrage (1995) showed that one can improve statistically naïve participants’ Bayesian inference by presenting information in a frequency format instead of a probability format. From an evolutionary viewpoint, they argued that the frequency format corresponds to the sequential way information is acquired in the natural environment, from animal foraging to neural networks. In relation to the present thesis, there is, indeed an important distinction between frequency and probability knowledge. While probability represents a more abstract concept, frequency information often represents actual encounters that carry affective value (or experiential value, see Epstein, 1994; Slovic et al., 2002). The encounter with an affective-laden event, in particular, registers the event, as well as the affective meaning (+ or - ) attached to that event. A classic demonstration of the automatic encoding of affective information (primary valuation) is the "mere exposure effect," which shows that people prefer certain options for no reasons other than they have been frequently exposed (Zajonc, 1968).

In our studies, the sign-frequency effect mainly concerned what Kahneman et al. (1997) termed decision utility. But there is strong evidence indicating that frequency effects play a major role in "experienced" utility as well. For example, research on subjective wellbeing has shown that several major self-report measures of happiness correlate much more 
strongly with frequent positive and infrequent negative events than with the intensity of the positive events (Diener, Sandvik, \& Pavot, 1991). This correspondence between decision utility and experience utility raises an interesting possibility that sign-frequency considerations in a decision can be rationally based on substantive criteria.

\section{Prescriptive Implications}

What have we learned about preference from the present study? At the heart of preference construction seems to be a primary valuation process that assigns affective value to the target object. This stage of valuation is reasonably stable. Therefore, across different situations, one can expect the same negative reaction toward information about fat in a food product. On the other hand, expressed preferences are highly susceptible to contextual influences. One source of contextual influences that has received a lot of attention is the framing. Another is the level of the descriptive detail as examined in our studies..

What do these contextual effects, framing and descriptive details, have in common? We believe that they reflect an important characteristic of affective valuation, namely that the primary valuation process is more sensitive and responsive to the immediate, local environment, than to the global situation. For example, people have a tendency to use the status quo as a reference point to classify information. Thus, a small loss of $\$ 10$ is perceived as a loss (-), despite a previous gain of \$20. In today’s American culture, one’s negative reaction to local information about "fat" is almost inevitable. One may be able to rectify this primary impression through diligent thinking, but not without effort. From this perspective, all decisions start at a "local” level, in the sense that the primary valuation process responds to the world as it is presented.

But, how should the world be presented? 
An option or alternative can be described in infinite layers of detail. Thus, a target object can be judged as a whole, or at the level of attributes, or sub-attributes, and so forth. Likewise, in terms of experienced utility, one can summarize and evaluate his/her experience at many different layers of detail. For example, the affective experiences of "a week’s vacation in Paris” can be evaluated as a whole, or day by day, hour by hour, and so forth. Normative theory does not distinguish these different layers of descriptions. A standard utilitarian interpretation of an affective episode (e.g., a week's vacation in Paris) is as a collection of momentary experiences summed over time (Parfit, 1984; Schelling, 1984). Logically, both a local and a global perspective refer to (or describe) the same affective episode. However, as the sign-frequency effect has indicated, the global evaluation of an event and the summation of its local components are not psychologically equivalent. What perspective one takes at the time of the valuation does matter.

From a prescriptive viewpoint, the discrepancy that arises from a change in perspective poses serious practical and ethical questions regarding how one should provide advice to people. For instance, health-care officers often need to prepare a brochure to better inform consumers about the pros and cons of available HMOs. Questions regarding how much information should be given and how much detail it should be presented have drawn much attention in the past (Hibbard, Slovic, \& Jewett, 1997; Hibbard, Peters, Slovic, Finucane, \& Tusler, 2001). In Studies 2, 3, and 5, the HMO question was taken out of an actual health plan brochure to simulate the choice situation that consumers actually face. These studies showed that people's expressed preference is contingent upon the level of detailed ratings they receive. What level of detail should be given? An expansion of details on selected attributes almost surely will lead to the manipulation of people's preferences. 
In the case of framing effects, the change in perspective is due to the shift of the reference point and its effect on the sign pattern. Both the HMO example and the vacation in Paris example discussed above illustrate the perspective change due to a change in the frequency of the valuation units. There is no normative or prescriptive guideline as to which perspective will better elicit the "true” preference. A sensible prescriptive intervention might be to present different perspectives to decision makers, in the hope that this can help people reconcile their inconsistent preferences. A problem with this approach is that it may be trying to fix something that is not broken. Recall the "one week vacation in Paris” example. In the course of the vacation, one may experience many negative experiences and few positive experiences because of various mishaps. After the vacation, however, the retrospective evaluation of the whole trip may be positive, because pleasant memories stand out while bad memories fade away. To try to reconcile these “inconsistencies” is to deny the legitimacy of one’s affective experience.

\section{ACKNOWLEDGEMENT}

Portions of this research were conducted as part of the first author's doctoral dissertation at the University of Oregon. We are grateful to the U.S. National Science Foundation for financial support of this research under Grants SBR 9422754, SBR 9876587, SES 0112158, and SES 0241313. 


\section{REFERENCES}

Chiu, I. C., \& Lin, S. (2002). The effects of reference point in choice under risk: A Relative Expected Value model. Unpublished manuscript.

Damasio, A. R. (1994). Descartes' error: Emotion, reason, and the human brain. New York: Avon.

Desvousges, W., Johnson, R., Dunford, R., Boyle, K. J., Hudson, S., \& Wilson, K.N. (1992). Measuring non-use damages using contingent valuation: An experimental evaluation accuracy. Research Triangle Institute Monograph, 92-1.

Diener, E., Sandvik, E., \& Pavot, W. (1991). Happiness is the frequency, not the intensity, of positive versus negative affect. In F. Strack, M. Argyle, \& N. Schwarz (Eds.), Subjective well-being (pp. 119-40). New York: Pergamon Press.

Epstein, S. (1994). Integration of the cognitive and psychodynamic unconscious. American Psychologist, 49, 709-724.

Estes, W. K. (1976a). Some functions of memory in probability learning and choice behavior. In G. W. Bower (ED.), The psychology of learning and motivation (Vol. 10, pp. 2-45). New York: Academic Press.

Estes, W. K. (1976b). The cognitive side of probability learning. Psychological Review, 83, 37-64.

Fischhoff, B., Slovic, P., \& Lichtenstein, S. (1978). Fault trees: Sensitivity of estimated failure probabilities to problem representation. Journal of Experimental Psychology: Human Perception and Performance, 4, 330-344.

Fredrickson, B., \& Kahneman, D. (1993). Duration neglect in retrospective evaluations of affective episodes. Journal of Personality and Social Psychology, 65, 45-55.

Gigerenzer, G., \& Hoffrage, U. (1995). How to improve bayesian reasoning without instruction: Frequency formats. Psychological Review, 102, 684-704.

Hasher, L., \& Rose, T. Z. (1984). Automatic processing of fundamental information: The case of frequency occurrence. American Psychologist, 39, 1372-1388.

Hibbard, J. H., Slovic, P., \& Jewett, J. J. (1997). Informing consumer decisions in health care: Implications from decision-making research. Milbank Quarterly, 75(3), 395414. 
Hibbard, J. H., Peters, E., Slovic P., Finucane, M. L., \& Tusler, M. (2001). Making health care quality report cards easier to use. The Joint Commision Journal on Quality Improvement, 27, 591-604.

Hintzman, D. L. (1976). Repetition and memory. In G. H. Bower (Ed.), The psychology of learning and motivation (Vol. 10, pp.47-91). New York: Academic Press.

Hsee, C. (1996). The evaluability principle: An explanation for preference reversals between joint and separate evaluations of alternatives. Organizational Behavior and Human Decision Processes, 67, 247-257.

Kahneman, D. (1992). Reference points, anchors, norms, and mixed feelings. Organizational Behavior and Human Decision Processes, 51, 296-312.

Kahneman, D., \& Knetsch, J. L. (1992). Valuing public goods: the purchase of moral satisfaction. Journal of Environmental Economics and Management, 22, 57-70.

Kahneman, D., Ritov, I., \& Schkade, D. (1999). Economic preferences or attitude expressions?: An analysis of dollar responses to public issues. Journal of Risk and Uncertainty, 19(1-3), 203-235.

Kahneman, D., Wakker, P. P., \& Sarin, R. (1997). Back to Bentham? Explorations of experienced utility. The Quarterly Journal of Economics, May, 375-405.

Levin, I. P., \& Gaeth. G. J. (1988). How consumers are affected by the faming of attribute information before and after consuming the product. Journal of Consumer Research, 15, 374-378.

Lin, S. (1999). Sign Theory: A theory of preference construction. Ph.D. dissertation, University of Oregon. Unpublished manuscript.

Oatley, K., \& Johnson-Laird, P. N. (1987). Toward a cognitive theory of emotion. Cognition and Emotion, 1, 29-50.

Osgood, C.E., Suci, G. S., \& Tannenbaum, P. H. (1957). The measurement of meaning. Urbana: University of Illinois Press.

Parfit, D. (1984). Reasons and persons. Oxford, UK: Clarendon Press.

Payne, J. W., Bettman, J. R., \& Schkade, D. A. (1999). Measuring constructed preferences: Towards a building code. Journal of Risk and Uncertainty, 19(1), 243-270.

Rottenstreich, Y., \& Tversky, A. (1997). Unpacking, repacking, and anchoring: Advances in support theory. Psychological Review, 104, 406-415. 
Schelling, T. C. (1984). Choice and consequence. Cambridge, MA: Harvard University Press.

Simon, H. A. (1955). A behavior model of rational choice. Quarterly Journal of Economics, 69, 99-118.

Simon, H. A. (1956). Rational choice and the structure of the environment. Psychological Review, 63, 129-138.

Simon, H. A. (1967). Motivational and emotional controls of cognition. Psychological Review, 74, 29-39.

Slovic, P. (1975). Choice between equally valued alternatives. Journal of Experimental Psychology: Human Perception and Performance, 1, 280-287.

Slovic, P. (1995). The construction of preference. American Psychologist, 50, 364-371.

Slovic, P., Finucane, M.L., Peters, E., \& MacGregor, D.G. (2002). The affect heuristic. In T. Gilovich, D. Griffin, \& D. Kahneman (Eds.), Heuristics and biases: The psychology of intuitive judgment (pp. 397-420). New York: Cambridge University Press.

Tversky, A., \& Kahneman, D. (1986). Rational choice and the framing of decisions. Journal of Business, 59, 251-278.

Tversky, A., \& Koehler, D. J. (1994). Support theory: A nonextensional representation of subjective probability, Psychological Review, 101, 547-567.

Tversky, A., Sattath, S., \& Slovic, P. (1988). Contingent weighting in judgment and choice, Psychological Review, 95, 371-384.

Von Nitzsch, R., \& Weber, M. (1993). The effect of attribute ranges on weights in multiattribute utility measurements. Management Science, 39, 937-943.

Weber, M., Eisenfuhr, F., \& von Winterfeldt, D. (1988). The effects of splitting attributes on weights in multiattribute utility measurement. Management Science, 34, 431-445.

Zajonc, R. B. (1968). Attitudinal effects of mere exposure. Journal of Personality and Social Psychology Monograph Supplement, 9, 1-28.

Zajonc, R. B. (1980). Feeling and thinking: Preferences need no inferences. American Psychologist, 35, 151-175. 
Table 1. Task Stimuli and Choice Percentages in Study 1

\begin{tabular}{lllll}
\hline \hline Pair \# & Stimuli* & Sign & Predicted Choice & Choice \% \\
\hline (1) & A: $(8,6)$ & $(++)$ & A & 86 \\
& B: $(6,9)$ & $(++)$ & & 14 \\
$(2)$ & A: $(8,4)$ & $(+-)$ & & 33 \\
& B: $(6,7)$ & $(++)$ & B & 67 \\
$(3)$ & A: $(6,6)$ & $(++)$ & A & 90 \\
& B: $(4,9)$ & $(-+)$ & & 10 \\
$(4)$ & A: $(3,1)$ & $(--)$ & A & 84 \\
& B: $(1,4)$ & $(--)$ & & 16 \\
\hline
\end{tabular}

Note: The first rating in each pair is typing quality, the second is speed. 
Table 2. Examples of positive partitioning in Study 2.

\section{Control version}

$\underline{\text { Attribute }}$

Picture Quality:

Sound Quality

Ease of Operation

Summarized version

$\underline{\text { Attribute }}$

Picture Quality:

Picture clarity

Color fidelity

Picture brightness

Picture contrast

Sound Quality

Ease of Operation

$\underline{\text { Detailed version }}$

Attribute

Picture Clarity

Color Fidelity

Picture Brightness

Picture contrast

Sound Quality

Ease of Operation
$\underline{\mathrm{TV} A}$

0

0

$\underline{\mathrm{TV} A}$

O

0

$\underline{\mathrm{TV} A}$

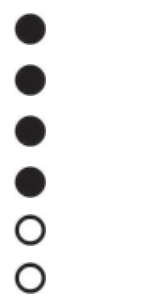

$\underline{\text { TV B }}$

$\underline{\mathrm{TV} B}$

$\underline{\text { TV B }}$

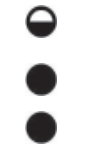

$\ominus$
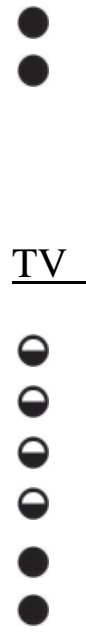
Table 3. Examples of negative partition in Study 2.

\section{Control version}

\begin{tabular}{|c|c|c|}
\hline Attribute & TV A & TV B \\
\hline Picture Quality: & 0 & $\theta$ \\
\hline Sound Quality & • & 0 \\
\hline Ease of Operation & - & 0 \\
\hline \multicolumn{3}{|l|}{ Summarized version } \\
\hline Attribute & TV A & TV B \\
\hline Picture Quality: & 0 & $\theta$ \\
\hline Picture clarity & & \\
\hline Color fidelity & & \\
\hline Picture brightness & & \\
\hline Picture contrast & & \\
\hline Sound Quality & - & 0 \\
\hline Ease of Operation & & 0 \\
\hline
\end{tabular}

\section{Detailed version}

$\begin{array}{lll}\text { Attribute } & \text { TV A } & \text { TV B } \\ \text { Picture Clarity } & 0 & \\ \text { Color Fidelity } & 0 & \bullet \\ \text { Picture Brightness } & 0 & \bullet \\ \text { Picture contrast } & 0 & \bullet \\ \text { Sound Quality } & \bullet & 0 \\ \text { Ease of Operation } & \bullet & 0\end{array}$


Table 4. Mean Preference Scores and Choice Percentages in Study 2.

\begin{tabular}{|c|c|c|c|c|c|c|}
\hline & \multicolumn{3}{|c|}{ Positive Partition } & \multicolumn{3}{|c|}{ Negative Partition } \\
\hline & & Rating & Choice & & Rating & Choice \\
\hline TV & Mean & (A\%) & $(\mathrm{B} \%)$ & Mean & (A\%) & $(\mathrm{B} \%)$ \\
\hline Control (C) & $\overline{6.8}$ & 17 & 81 & $\overline{3.8}$ & 67 & 17 \\
\hline Summarized (S) & 6.2 & 22 & 71 & 4.8 & 42 & 31 \\
\hline Detailed (D) & 5.0 & 39 & 54 & 6.5 & 11 & 71 \\
\hline \multicolumn{7}{|l|}{ Predicted Effects: } \\
\hline $\mathrm{D}-\mathrm{S}$ & \multicolumn{3}{|c|}{$-1.2^{* *}$} & \multicolumn{3}{|c|}{$1.7^{* *}$} \\
\hline$D-C$ & \multirow{2}{*}{\multicolumn{3}{|c|}{$\begin{array}{l}-1.8^{* * *} \\
-0.6\end{array}$}} & \multicolumn{3}{|c|}{$2.7 * * *$} \\
\hline $\mathrm{S}-\mathrm{C}$ & & & & $1.0^{* *}$ & & \\
\hline \multicolumn{7}{|l|}{ HMO } \\
\hline Control (C) & 6.0 & 33 & 60 & 4.5 & 48 & 23 \\
\hline Summarized (S) & 6.9 & 16 & 82 & 4.4 & 49 & 26 \\
\hline Detailed (D) & 5.5 & 38 & 59 & 5.4 & 32 & 55 \\
\hline \multicolumn{7}{|l|}{ Predicted Effects: } \\
\hline $\mathrm{D}-\mathrm{S}$ & \multicolumn{3}{|l|}{$-1.4^{* *}$} & \multicolumn{3}{|l|}{$1.0^{* *}$} \\
\hline$D-C$ & \multirow{2}{*}{\multicolumn{3}{|c|}{$\begin{array}{l}-0.5 \\
0.9 *\end{array}$}} & \multicolumn{3}{|l|}{$0.9 *$} \\
\hline$S-C$ & & & & -0.1 & & \\
\hline \multicolumn{7}{|l|}{ Budget Committee } \\
\hline Control (C) & 6.0 & 29 & 65 & 4.9 & 48 & 46 \\
\hline Summarized (S) & 6.2 & 24 & 69 & 4.7 & 55 & 35 \\
\hline Detailed (D) & 5.2 & 45 & 52 & 6.2 & 23 & 68 \\
\hline \multicolumn{7}{|l|}{ Predicted Effects: } \\
\hline $\mathrm{D}-\mathrm{S}$ & \multicolumn{3}{|l|}{-1.0} & \multicolumn{3}{|l|}{$1.5^{* *}$} \\
\hline$D-C$ & \multicolumn{3}{|l|}{-0.8} & \multicolumn{3}{|l|}{$1.3^{* *}$} \\
\hline$S-C$ & \multicolumn{3}{|l|}{0.2} & \multicolumn{3}{|l|}{-0.2} \\
\hline \multicolumn{7}{|l|}{ Used Car } \\
\hline Control (C) & 4.3 & 60 & 37 & 6.0 & 21 & 65 \\
\hline Summarized (S) & 4.2 & 62 & 35 & 6.0 & 16 & 69 \\
\hline Detailed (D) & 2.7 & 79 & 16 & 7.3 & 7 & 89 \\
\hline \multicolumn{7}{|l|}{ Predicted Effects: } \\
\hline $\mathrm{D}-\mathrm{S}$ & \multicolumn{3}{|l|}{$-1.5^{* *}$} & \multicolumn{3}{|l|}{$1.3^{* *}$} \\
\hline$D-C$ & \multirow{2}{*}{\multicolumn{3}{|c|}{$-1.6^{* *}$}} & \multicolumn{3}{|l|}{$1.3^{* *}$} \\
\hline$S-C$ & & & & \multicolumn{3}{|l|}{0.0} \\
\hline
\end{tabular}

Note: 1 . Lower preference scores represent a preference for option A.

2.The direction of predicted effects (S-C) was based on the availability hypothesis.

3. LSD procedure was used to test the Predicted Effects, where * indicates $\mathrm{p}<.05$, $* *$ indicates $\mathrm{p}<.01$, and $* * *$ indicates $\mathrm{p}<.001$. 
Table 5. Examples with Positive Partition in Study 3

Example 5.1 Detailed version

Attribute

Picture Clarity

Color fidelity

Picture Brightness

Picture contrast

Sound Quality

Sound Fidelity

Surround Sound Effect

Bass Response

Speaker Power

Ease of Operation

Example 5.3 Summarized version

$\underline{\text { Attribute }}$

$\underline{\text { TV A }}$

Picture Quality:

Picture clarity

Color fidelity

Picture brightness

Picture contrast

Sound Quality

Sound Fidelity

Surround Sound Effect

Bass Response

Speaker Power

Ease of Operation

$\underline{\mathrm{TV}} \mathrm{A}$

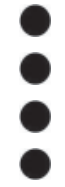

O

O
Ease of Operation

Example 5.4 PLI version

$\underline{\text { Attribute }}$

Sound Fidelity

Surround Sound Effect

Base Response

Speaker Power

Picture Quality

Picture Clarity

Color Fidelity

Picture Brightness

Picture Contrast

Ease of Operation $\underline{\text { TV A }}$

TV A

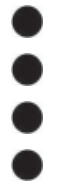

O

O

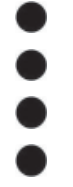

O

O 
Table 6. Examples of partitioning average attribute as positive partition in Study 3

Example 6.1 Detailed version

Attribute

Picture Clarity

Color fidelity

Picture Brightness

Picture contrast

Sound Quality

Sound Fidelity

Surround Sound Effect

Bass Response

Speaker Power

Ease of Operation

Example 6.3 Summarized version

Attribute

Picture Quality:

Picture clarity

Color fidelity

Picture brightness

Picture contrast

Sound Quality

Sound Fidelity

Surround Sound Effect

Bass Response

Speaker Power

Ease of Operation

$\underline{\text { TV B }}$

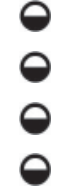

O
Sound Fidelity

Surround Sound Effect

Bass Response

Speaker Power

Picture Quality

Picture Clarity

Color Fidelity

Picture Brightness

Picture Contrast

Ease of Operation

Example 6.4 PLI version

$\underline{\text { Attribute }}$

Sound Fidelity

Surround Sound Effect

Base Response

Speaker Power

Picture Quality

Picture Clarity

Color Fidelity

Picture Brightness

Picture Contrast

Ease of Operation
TV B

$\underline{\text { TV B }}$

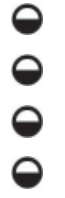

O

O

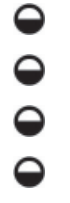

O

O 
Table 7. Examples of partitioning average attribute as negative partition in Study 3

Example 7.1 Detailed version

$\underline{\text { Attribute }}$

Picture Clarity

Color fidelity

Picture Brightness

Picture contrast

Sound Quality

Sound Fidelity

Surround Sound Effect

Bass Response

Speaker Power

Ease of Operation

Example 7.3 Summarized version

Attribute

Picture Quality:

Picture clarity

Color fidelity

Picture brightness

Picture contrast

Sound Quality

Sound Fidelity

Surround Sound Effect

Bass Response

Speaker Power

Ease of Operation
Example 7.2 PLI version

Attribute

TV B

Sound Fidelity
Surround Sound Effect
Bass Response
Speaker Power
Picture Quality
Picture Clarity
Color Fidelity
Picture Brightness
Picture Contrast
Ease of Operation

Example 7.4 PLI version

Attribute

TV B

Sound Fidelity

Surround Sound Effect

Base Response

Speaker Power

Picture Quality

Picture Clarity

Color Fidelity

Picture Brightness

Picture Contrast

Ease of Operation 
Table 8. Mean WTP Values

Mean WTP Values in the Positive Partition Condition

\begin{tabular}{|c|c|c|c|c|}
\hline & \multicolumn{2}{|c|}{$\begin{array}{l}\text { Option A } \\
\text { (Splitting Good Attribute) }\end{array}$} & \multicolumn{2}{|c|}{$\begin{array}{l}\text { Option B } \\
\text { (Splitting Average Attribute) }\end{array}$} \\
\hline & $\underline{\mathrm{TV}}$ & $\underline{\mathrm{HMO}}$ & $\underline{\mathrm{TV}}$ & $\underline{\mathrm{HMO}}$ \\
\hline Detailed (D) & 216 & 202 & 115 & 81 \\
\hline Summarized (S) & 151 & 136 & 74 & 61 \\
\hline Important D (PLI) & 170 & 149 & 105 & 67 \\
\hline \multicolumn{5}{|l|}{ Predicted Effect } \\
\hline $\begin{array}{l}\text { Sign-Frequency } \\
\text { (D-S) }\end{array}$ & $65^{* * *}$ & $66 * * *$ & $41^{* * *}$ & $20 * * *$ \\
\hline $\begin{array}{l}\text { Important Dimension } \\
\text { (D-PLI) }\end{array}$ & $46^{* * *}$ & $53^{* * *}$ & 10 & $14^{*}$ \\
\hline $\begin{array}{l}\text { Frequency-Important D } \\
\text { (PLI- S) }\end{array}$ & 19 & 13 & $31^{* * *}$ & 6 \\
\hline
\end{tabular}

Mean WTP Values in the Negative Partition Condition

\begin{tabular}{|c|c|c|c|c|}
\hline & \multicolumn{2}{|c|}{$\begin{array}{l}\text { Option A } \\
\text { (Splitting Bad Attribute) }\end{array}$} & \multicolumn{2}{|c|}{$\begin{array}{l}\text { Option B } \\
\text { (Splitting Average Attribute) }\end{array}$} \\
\hline & $\underline{\mathrm{TV}}$ & $\underline{\mathrm{HMO}}$ & $\underline{\mathrm{TV}}$ & $\underline{\mathrm{HMO}}$ \\
\hline Detailed (D) & 118 & 111 & 254 & 251 \\
\hline Summarized (S) & 195 & 159 & 313 & 272 \\
\hline Important D (PLI) & 156 & 153 & 303 & 275 \\
\hline \multicolumn{5}{|l|}{ Predicted Effect } \\
\hline $\begin{array}{l}\text { Sign-Frequency } \\
\text { (S - D) }\end{array}$ & $77 * * *$ & $48 * * *$ & $59 * * *$ & $21 *$ \\
\hline $\begin{array}{l}\text { Important Dimension } \\
\text { (PLI - D) }\end{array}$ & $38 * * *$ & $42 * * *$ & $49 * * *$ & $24^{*}$ \\
\hline $\begin{array}{l}\text { Frequency-Important D } \\
\text { (S -PLI) }\end{array}$ & $39 * *$ & 6 & 10 & -3 \\
\hline
\end{tabular}

Note: 1. Cell entries are WTP in dollars (top three rows) and difference in WTP (bottom three rows).

2. LSD procedure was used to test the Predicted Effects, where * indicate $\mathrm{p}<.05$, **indicate $\mathrm{p}<.01$, and $* * *$ indicate $\mathrm{p}<.001$. 
Table 9. Mean Ratings of Relative Importance in Study 3

TV:

Summarized

Detailed

\begin{tabular}{|cccc|}
\multicolumn{4}{c}{} \\
\multicolumn{1}{|c}{} \\
Clarity & Fidelity & Brightness & Contrast \\
26 & 14 & 12 & 11 \\
\hline
\end{tabular}

PLI
Sound Quality 35

24

\section{Ease of Operation}

20

13

14

\begin{tabular}{|cccc|}
\multicolumn{1}{|c}{$\downarrow$} & & & \\
\hline Fidelity & Surround & Bass & Speaker \\
17 & 13 & 10 & 12 \\
\hline
\end{tabular}

Customer Service

(65)

Detailed

\begin{tabular}{|ccc|}
\multicolumn{1}{c}{$\downarrow$} \\
\hline Thoroughness & Receive & Approval \\
27 & 21 & 16 \\
\hline
\end{tabular}

PLI
35
25

17

Preventive Care

27

17

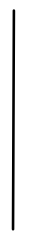

\begin{tabular}{|ccc|}
\hline \multicolumn{1}{|c}{} & \multicolumn{2}{c}{20} \\
\hline $\begin{array}{c}\text { Satisfaction } \\
15\end{array}$ & Choice & Approval \\
15 & 15 \\
\hline
\end{tabular}

Note. The number given in parentheses represents the sum of the split attributes in the detailed version. 
Sign Theory

Table 10. TV Preferences in Study 4

\begin{tabular}{|c|c|c|c|c|c|c|c|c|}
\hline \multirow[b]{3}{*}{ Versions } & \multirow[b]{3}{*}{ Mean } & \multicolumn{3}{|c|}{ Positive Partition } & \multicolumn{4}{|c|}{ Negative Partition } \\
\hline & & \multicolumn{2}{|c|}{ Rating } & Choice & \multicolumn{2}{|c|}{ Rating } & \multicolumn{2}{|c|}{ Choice } \\
\hline & & $\underline{\mathrm{A} \%}$ & $\mathrm{~B} \%$ & ndifference & Mean & $\mathrm{A} \%$ & B\% & Indiffel \\
\hline \multicolumn{9}{|c|}{ With \% Information } \\
\hline Summarized & 5.26 & 19 & 80 & 1 & 3.62 & 47 & 32 & 19 \\
\hline Detailed & 4.71 & 30 & 68 & 1 & 5.18 & 13 & 75 & 10 \\
\hline \multicolumn{9}{|c|}{ Without \% Information } \\
\hline Summarized & 4.87 & 28 & 70 & 2 & 3.55 & 43 & 37 & 18 \\
\hline Detailed & 4.34 & 42 & 55 & 3 & 4.97 & 15 & 68 & 15 \\
\hline
\end{tabular}

Note: Lower preference rating scores represent a preference for TV A. 
Table 11. Choice 1 in Study 5 (Summarized Format).

Attributes:

\section{Customer Service}

Ease of making an appointment by phone

Courtesy of medical office staff

Helpfulness of medical office staff

Preventive Medical Care

Ease of getting immunizations (e.g. flu shots, hepatitis shots)

Ease of getting screening tests (e.g., cholesterol tests, pap smears)

Ease of getting physical exams

\section{Treatment Quality}

Patients receive thorough treatment

Patients get to see a specialist when needed

Treatments are explained well to patients
HMO HMO

A B

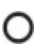

0

$\begin{array}{ll}0 & 0 \\ 0 & 0 \\ 0 & 0\end{array}$


Table 12. Choice 2 in Study 5 (Detailed Format).

Attributes:

HMO HMO

A B

\section{Customer Service}

Ease of making an appointment by phone

Courtesy of medical office staff

Helpfulness of medical office staff

Preventive Medical Care

Ease of getting immunizations (e.g. flu shots, hepatitis shots)

Ease of getting screening tests (e.g., cholesterol tests, pap smears)

Ease of getting physical exams

\section{Treatment Quality}

Patients receive thorough treatment

Patients get to see a specialist when needed

Treatments are explained well to patients 
Table 13. Choices of Health Plans under Two Different Display Formats

\begin{tabular}{|c|c|c|c|c|c|c|}
\hline & \multicolumn{3}{|c|}{$\begin{array}{l}\text { Group 1: Choice } 1 \text { then Choice } 2 \\
\qquad(\mathrm{~N}=57)\end{array}$} & \multicolumn{3}{|c|}{$\begin{array}{l}\text { Group 2: Choice } 2 \text { then Choice } 1 \\
\qquad(\mathrm{~N}=56)\end{array}$} \\
\hline & $\begin{array}{c}\% \\
\text { choosing A }\end{array}$ & $\begin{array}{c}\% \\
\text { choosing B }\end{array}$ & $\begin{array}{c}\% \text { no } \\
\text { preference }\end{array}$ & $\begin{array}{c}\% \\
\text { choosing A }\end{array}$ & $\begin{array}{c}\% \\
\text { choosing B }\end{array}$ & $\begin{array}{c}\% \text { no } \\
\text { preference }\end{array}$ \\
\hline Choice 1 & 28.1 & 68.4 & 3.5 & 16.1 & 76.8 & 7.1 \\
\hline Choice 2 & 36.8 & 59.6 & 3.5 & 37.5 & 53.6 & 8.9 \\
\hline & $\begin{array}{rr} & C h \\
34 \text { partici } \\
18 \text { shifted } \\
5 \text { shifted } \\
7 \text { prefer } \\
2 \text { prefer }\end{array}$ & $\begin{array}{l}\text { ice } 1 \text { vs. Cho } \\
\text { ants made sa } \\
\text { toward A } \\
\text { toward B } \\
\text { ice reversal ( } \\
\text { lce reversal ( }\end{array}$ & $\begin{array}{l}\text { e } 2 \\
\text { e choice } \\
\text { om B to A) } \\
\text { om A to B) }\end{array}$ & $\begin{array}{r}\text { Ch } \\
34 \text { partici } \\
20 \text { shiftec } \\
2 \text { shiftec } \\
12 \text { prefere } \\
0 \text { prefere }\end{array}$ & $\begin{array}{l}\text { ice } 2 \text { vs. Cho } \\
\text { ants made sa } \\
\text { toward B } \\
\text { toward A } \\
\text { ce reversal ( } \\
\text { ce reversal ( }\end{array}$ & $\begin{array}{l}\text { e } 1 \\
\text { e choice } \\
\text { m A to B) }\end{array}$ \\
\hline
\end{tabular}


Table 14. Mean Importance Weights for Three HMO Attributes

\begin{tabular}{lcccc}
\hline \multicolumn{1}{c}{ Attribute } & \multicolumn{2}{c}{ Group 1 } & \multicolumn{2}{c}{ Group 2 } \\
& Choice 1 & Choice 2 & Choice 2 & Choice 1 \\
\hline Importance of customer service & 18.1 & 17.9 & 16.5 & 18.3 \\
Importance of preventive medical care & 30.5 & 31.9 & 28.2 & 29.0 \\
Importance of treatment quality & 51.3 & 50.2 & 55.3 & 52.7 \\
\hline
\end{tabular}

